\title{
2,4-Furfurylidene-D-sorbitol and its tetra-methyl ether: synthesis, conformational studies, and radical scavenging activity
}

\author{
Pierangela Ciuffreda, ${ }^{\mathrm{a} *}$ Andrea Brizzolari, ${ }^{\mathrm{b}}$ Silvana Casati, ${ }^{\mathrm{a}}$ Ivano Eberini, ${ }^{\mathrm{a}, \mathrm{c}}$ \\ Luca Palazzolo, ${ }^{\mathrm{c}}$ Chiara Parravicini, ${ }^{\mathrm{c}}$ and Enzo Santaniello ${ }^{\mathrm{b}, \mathrm{d}}$
}

\author{
aDipartimento di Scienze Biomediche e Cliniche "L. Sacco", Università degli Studi di Milano, \\ Via G.B. Grassi 74, 20157 Milano, Italy \\ ${ }^{b}$ Dipartimento di Scienze della Salute, Università degli Studi di Milano, Via Di Rudinì 8, 20142 \\ Milano, Italy \\ ${ }^{c}$ Dipartimento di Scienze Farmacologiche e Biomolecolari, Università degli Studi di Milano, Via \\ Balzaretti, 9/11/13, 20133 Milano, Italy \\ ${ }^{d}$ Department of Biomedical Sciences, Humanitas University, Via Manzoni 113, 20089 Rozzano - \\ Milano, Italy \\ E-mail: pierangela.ciuffreda@unimi.it
}

DOI:http://dx.doi.org/10.3998/ark.5550190.p009.690

\begin{abstract}
The structure of 1-[2-(furan-2-yl)-5-hydroxy-6-(hydroxymethyl)-1,3-dioxan-4-yl]ethane-1,2-diol] (2,4-furfurylidene-D-sorbitol) and its tetra-methyl ether was established by a detailed NMR analysis. The conformational structure for both compounds was confirmed by in silico studies based both on Density Functional Theory (DFT) and on classical molecular dynamics approaches. The scavenging activity against hydroxyl radicals $(\cdot \mathrm{OH})$ of compounds was established by the 2deoxyribose degradation assay.
\end{abstract}

Keywords: 2,4-Furfurylidene-D-sorbitol, 2,4-furfurylidene-D-sorbitol tetra-methyl ether, conformational studies, NMR spectroscopy, molecular modeling, hydroxyl radicals scavenging activity

\section{Introduction}

1-[2-(furan-2-yl)-5-hydroxy-6-(hydroxymethyl)-1,3-dioxan-4-yl]ethane-1,2-diol (1) and its tetramethyl ether 2 (Figure 1) are 1,3-dioxane cyclic acetals that were claimed to prevent radical-caused skin aging. ${ }^{1}$ 


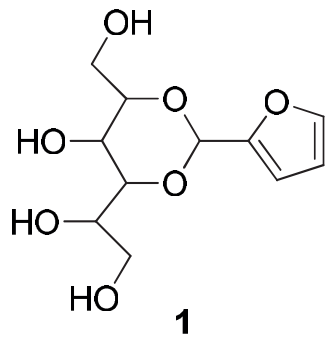<smiles>COCC1OC(c2ccco2)OC(C(COC)OC)C1OC</smiles>

Figure 1. Structure of 2,4-furfurylidene-D-sorbitol (1-[2-(furan-2-yl)-5-hydroxy-6(hydroxymethyl)-1,3-dioxan-4-yl]ethane-1,2-diol) (1) and its tetra-methyl ether 2.

Although both compounds $\mathbf{1}$ and $\mathbf{2}$ have been proposed for cosmetic and dermatological preparation in the original patent, ${ }^{1}$ only compound $\mathbf{1}$ has found practical applications as an active ingredient of anti-aging cosmetic preparations and for dermatological applications in radicalassociated skin diseases. ${ }^{2-5}$ Compound 1 was named originally 2,4-furfurylidene-D-sorbitol following the numbering of the D-sorbitol structure (Figure 2). ${ }^{6}$
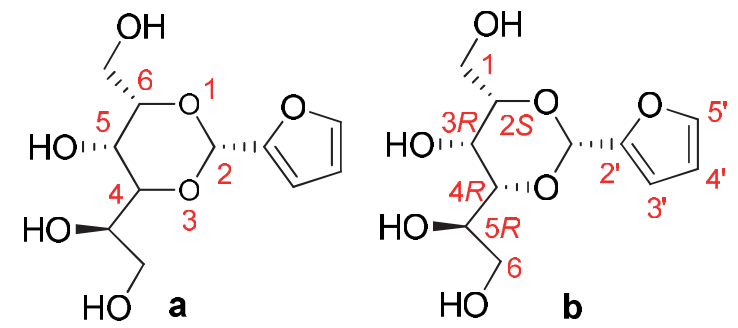

Figure 2. a: IUPAC numbering of 1-[2-(furan-2-yl)-5-hydroxy-6-(hydroxymethyl)-1,3-dioxan-4yl]ethane-1,2-diol (1); b: following the numbering of the hexitol portion of the structure, compound $\mathbf{1}$ is named 2,4-furfurylidene-D-sorbitol.

The first synthesis of 2,4-furfurylidene-D-sorbitol (1) from D-sorbitol (3) and furfural (4) in the presence of an acid catalyst (Scheme 1) dates back to $1937 .{ }^{7}$

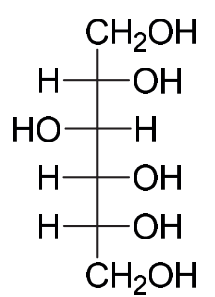

3

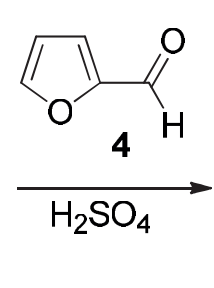<smiles>OC[C@H](O)[C@H]1O[C@@H](c2ccco2)O[C@H](CO)[C@@H]1O</smiles>

Scheme 1. Synthesis of compound 1.

The acetal $\mathbf{l}$ was obtained from a mixture of reaction products that contains variable amounts 
of cyclic di- and tri-acetals, as confirmed by other authors. ${ }^{6,8}$ The six membered 1,3-dioxane structure of compound 1 was originally proposed on the basis of its chemical transformation into L-xylose ${ }^{6,9}$ and $60 \mathrm{MHz}$ NMR analysis of the product. ${ }^{6}$ However, for a cyclic structure like the one that characterizes compounds $\mathbf{1}$ and $\mathbf{2}$ several conformations are possible, but this aspect has not been investigated up to now.

Concerning the anti-radical activity of 2,4-furfurylidene-D-sorbitol (1), the claimed protection from the free radical-caused skin damage initially proposed for this compound ${ }^{1}$ has been demonstrated using an in vitro model of fibroblast cultures exposed to tert-butyl hydroperoxide. ${ }^{10}$ The scavenging activity of compound $\mathbf{1}$ against the hydroxyl radical $\bullet \mathrm{OH}^{11,12}$ and other harmful radicals ${ }^{13}$ was later demonstrated by $\gamma$-pulsed radiolysis studies.

For the tetra-methyl ether $\mathbf{2}$ claimed in the cited patent, ${ }^{1}$ no synthetic procedure was described and no preparation of the compound has been ever published. Nonetheless, interesting biological activities related to anti-radical properties of this compound were proposed, ${ }^{14}$ including the protection against acute toxicity due to Amanita phalloides ingestion in mice. ${ }^{15}$

In the present paper, we describe the syntheses of 2,4-furfurylidene-D-sorbitol (1) and of the tetra-methyl ether 2. From our $500 \mathrm{MHz}{ }^{1} \mathrm{H}$ - and ${ }^{13} \mathrm{C}-\mathrm{NMR}$ studies on the conformations of the cyclic acetals $\mathbf{1}$ and 2, a structure was proposed for both compounds. The structures were confirmed and interpreted by in silico studies based both on Density Functional Theory (DFT) and on classical molecular dynamics approaches. Finally, we present an evaluation of the scavenging activity of compounds $\mathbf{1}$ and $\mathbf{2}$ and other structurally related molecules against hydroxyl radicals $(\cdot \mathrm{OH})$.

\section{Results and Discussion}

\section{Synthesis of 2, 4-Furfurylidene-D-sorbitol (1) and its tetra-methyl ether 2.}

The synthesis of 2,4-furfurylidene-D-sorbitol (1) was performed according to Ruskin and Hockett ${ }^{9}$ (Scheme 1) and afforded $70 \%$ yields of pure product after crystallization from cold water. Other products (cyclic di- and tri-acetals) ${ }^{6,8}$ were probably present in the mother liquor, but no effort was done to isolate them. The preparation of the tetra-methyl ether $\mathbf{2}$ (Scheme 2) was cumbersome, due to the formation of products of partial methylation. The complete methylation of compound $\mathbf{1}$ in water could be achieved only using a large excess of dimethyl sulphate in an aqueous solution of $\mathrm{NaOH}$. However, product recovery was complicated by the solubility of the tetra-methyl ether 2 in water $(34.5 \mathrm{~g} / \mathrm{L})$ and by the formation of large amounts of sodium sulphate. Consequently, the experimental procedure required many purification steps and the pure product was obtained in 30 $40 \%$ overall yield. 


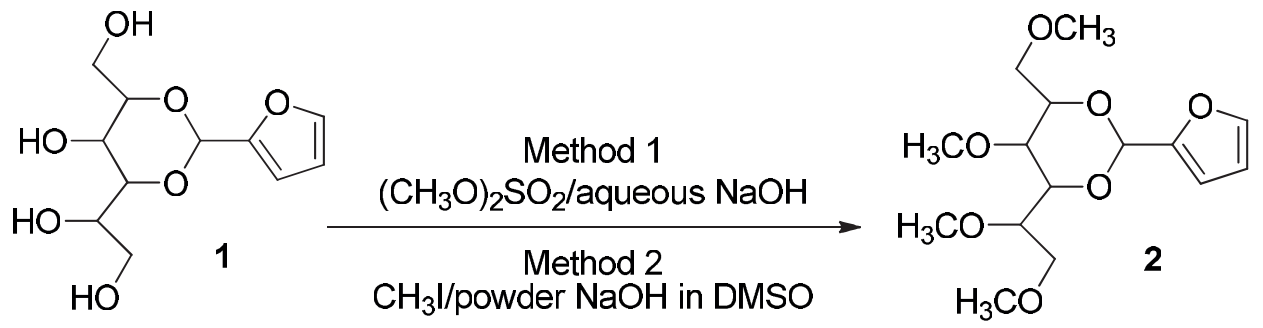

Scheme 2. Synthesis of compound 2.

The methylation reaction with methyl iodide $\mathrm{CH}_{3} \mathrm{I}$ in a non-aqueous ambient was complicated by the fact that 2,4-furfurylidene-D-sorbitol (1) shows a good solubility in water $(55.5 \mathrm{~g} / \mathrm{L})$ and is practically insoluble in the organic solvents commonly used for this reaction. Furthermore, an excess of $\mathrm{CH}_{3} \mathrm{I}$ was required to overcome the formation of partially methylated products. Nonetheless, the methylation of compound $\mathbf{1}$ was realized in anhydrous DMSO and powdered $\mathrm{NaOH}$ as a base. The work up was further complicated by the water solubility of the tetra-methyl ether $\mathbf{2}$, but a pure product was obtained after a few crystallizations with cold water/methanol mixtures. Yields were comparable with those obtained by the dimethyl sulphate method in water $(30-40 \%)$.

\section{NMR analysis of 2,4-furfurylidene-D-sorbitol (1) and its tetra-methyl ether 2}

We have investigated the structure of compounds 1 and 2 by $500 \mathrm{MHz}-\mathrm{NMR}$ spectroscopy, through proton and carbon 1D NMR spectra, as well as by 2D NMR homo-correlation (COSY) and hetero-correlation (HMQC and $\mathrm{HMBC}$ ) experiments. For overlapped signals of hydrogen atoms the 1D homonuclear Hartmann-Hahn coherence transfer technique (HOHAHA) ${ }^{16}$ was used to obtain the chemical shifts and coupling constants.

The experiments were carried out in two solvents (DMSO- $d_{6}$ and $\mathrm{D}_{2} \mathrm{O}$ ) and Table 1 and 2 report the assignments of all signals. In the description and interpretation of the signals, we found more convenient the numbering that refers to the hexitol portion of the structure (Figure 2). Consequently, the acetal hydrogen is here indicated as $\mathrm{H}^{\text {acetal }}$. In the accompanying supporting material, the most significant spectra are shown.

Specifically, in Table 1 all ${ }^{1} \mathrm{H}-\mathrm{NMR}$ data $(\delta$, ppm; $J, \mathrm{~Hz})$ for compounds $\mathbf{1}$ and $\mathbf{2}$ are reported as $\mathbf{1 a}$ and $\mathbf{2 a}$ for experiments in DMSO- $d_{6}$ and as $\mathbf{1 b}$ and $\mathbf{2 b}$ for experiments in $\mathrm{D}_{2} \mathrm{O}$ solutions. In DMSO- $d_{6}$ solution of compound 1 four extra signals, two doublets and two triplets, at $\delta 4.40(d)$, $4.41(t), 4.67(t)$ and $4.71(d)$ were observed and readily assigned to the four free $\mathrm{OH}$ present in the structure. 
Table 1. ${ }^{1} \mathrm{H}-\mathrm{NMR}$ data $(\delta \text {, ppm; } J, \mathrm{~Hz})^{\mathrm{a}, \mathrm{b}}$ in $\operatorname{DMSO}_{-} d_{6}(\mathbf{1} \mathbf{a}$ and $\mathbf{2 a})$ and $\mathrm{D}_{2} \mathrm{O}$ solutions $(\mathbf{1} \mathbf{b}$ and $\mathbf{2 b})$

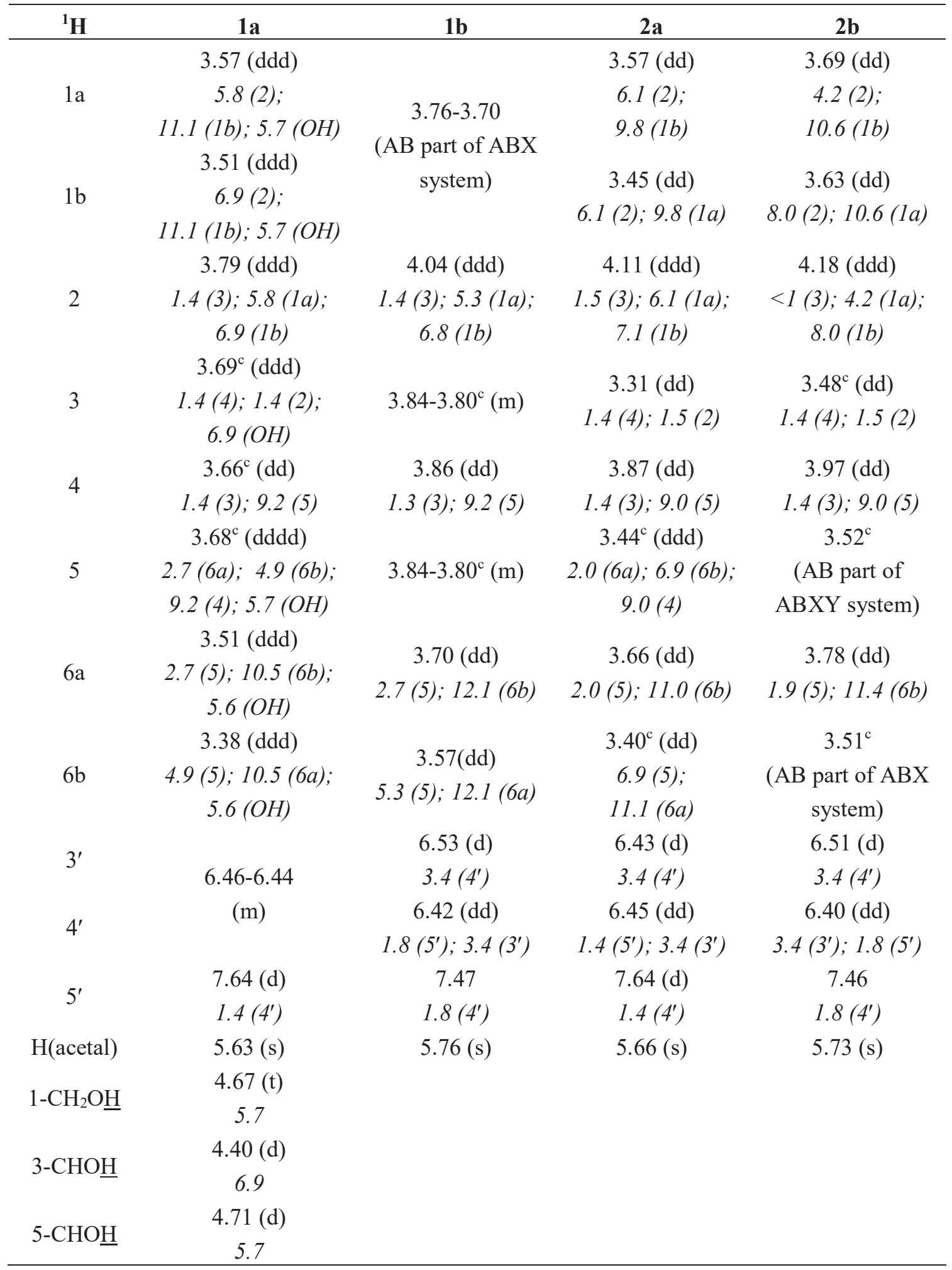

Table 1 (continued) 


\begin{tabular}{ccccc}
\hline${ }^{1} \mathbf{H}$ & $\mathbf{1 a}$ & $\mathbf{1 b}$ & $\mathbf{2 a}$ & $\mathbf{2 b}$ \\
\hline $6-\mathrm{CH}_{2} \mathrm{O} \underline{\mathrm{H}}$ & $4.41(\mathrm{t})$ & & \\
$1-\mathrm{CH}_{3}$ & 5.6 & & & \\
$3-\mathrm{CH}_{3}$ & & 3.30 & 3.33 \\
$5-\mathrm{CH}_{3}$ & & 3.40 & 3.45 \\
$6-\mathrm{CH}_{3}$ & & 3.37 & 3.39 \\
\hline
\end{tabular}

${ }^{\mathrm{a}}$ Multiplicity in parentheses. ${ }^{\mathrm{b}}$ Coupling constants $(J)$ in italics. ${ }^{\mathrm{c}}$ Overlapped signals, from n.O.e. and/or HOHAHA spectra.

In Table 2, ${ }^{13} \mathrm{C}-\mathrm{NMR}$ data $(\delta$, ppm) for compounds $\mathbf{1}$ and $\mathbf{2}$ are reported as $\mathbf{1 a}$ and $\mathbf{2 a}$ for experiments in DMSO- $d_{6}$ and as $\mathbf{1} \mathbf{b}$ and $\mathbf{2} \mathbf{b}$ for experiments in $\mathrm{D}_{2} \mathrm{O}$ solutions.

Table 2. ${ }^{13} \mathrm{C}-\mathrm{NMR}$ data $(\delta$, ppm $)$ a in DMSO- $d_{6}(\mathbf{1 a}$ and $\mathbf{2 a})$ and $\mathrm{D}_{2} \mathrm{O}$ solutions $(\mathbf{1} \mathbf{b}$ and $\mathbf{2 b})$

\begin{tabular}{lcccc}
\hline \multicolumn{1}{c}{${ }^{13} \mathbf{C}$} & $\mathbf{1 a}$ & $\mathbf{1 b}$ & $\mathbf{2 a}$ & \multicolumn{1}{c}{$\mathbf{2 b}$} \\
\hline 1 & 61.2 & 61.3 & 71.3 & 71.2 \\
2 & 81.3 & 80.7 & 78.2 & 78.6 \\
3 & 61.9 & 62.2 & 72.2 & 72.4 \\
4 & 79.7 & 78.9 & 77.6 & 77.2 \\
5 & 69.4 & 68.7 & 77.3 & 76.9 \\
6 & 62.8 & 62.3 & 70.2 & 68.0 \\
$2^{\prime}$ & 151.5 & 149.1 & 151.0 & 148.9 \\
$3^{\prime}$ & 108.1 & 109.1 & 108.2 & 109.0 \\
$4^{\prime}$ & 110.7 & 110.5 & 110.7 & 110.5 \\
$5^{\prime}$ & 142.9 & 143.5 & 143.2 & 143.5 \\
$\mathrm{C}^{\prime}(\mathrm{acetal})$ & 95.2 & 95.2 & 94.8 & 95.1 \\
$1-\mathrm{CH}_{3}$ & - & & $59.2^{\mathrm{b}}$ & $58.9^{\mathrm{b}}$ \\
$3-\mathrm{CH}_{3}$ & - & & $60.4^{\mathrm{b}}$ & $60.5^{\mathrm{b}}$ \\
$5-\mathrm{CH}_{3}$ & - & & $57.0^{\mathrm{b}}$ & $56.4^{\mathrm{b}}$ \\
$6-\mathrm{CH}_{3}$ & - & & $58.9^{\mathrm{b}}$ & $58.4^{\mathrm{b}}$ \\
\hline
\end{tabular}

${ }^{a}$ The uncertainties in the measurements of ${ }^{13} \mathrm{C}$ chemical shifts are $\pm 0.2 \mathrm{ppm}$. ${ }^{\mathrm{b}}$ Assigned based on gHMBC spectra.

The structures of compounds $\mathbf{1}$ and $\mathbf{2}$ as established by NMR studies are shown in Figure 3. In order to determine the conformation of the 1,3-dioxane ring, n.O.e. experiments were performed in DMSO- $d_{6}$. 


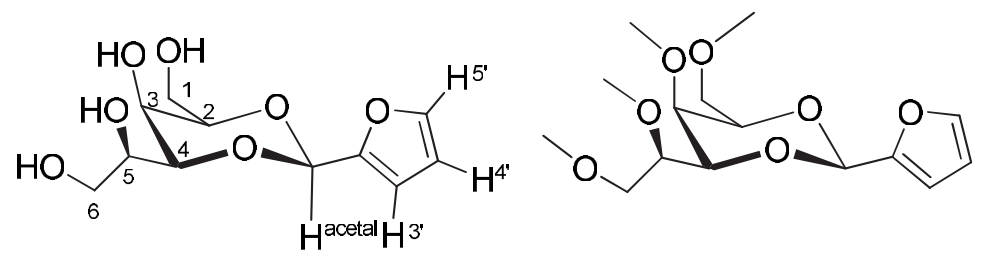

Figure 3. Positions of the hydrogen and carbon atoms in the hexitol portion of the 1,3-dioxane structure.

The experimentally observed n.O.e. for compounds $\mathbf{1}$ and $\mathbf{2}$ are summarized in Tables 3 and 4 . In particular, starting from the acetal hydrogen $(\delta 5.63 \mathrm{ppm}, \mathrm{s})$ indicated as $\mathrm{H}^{\text {acetal }}$ in Figure 3 , the irradiation of this signal exhibits in the n.O.e. spectrum an influence on signals at $\delta 3.79$ and $\delta 3.66$ corresponding to H-2 and H-4 and on signal centered at $\delta 6.45$ corresponding to H-3' (Figure 3 ). This indicates that both protons are axial as is $\mathrm{H}^{\text {acetal }}$. This observation enables us to determine that the furan ring is equatorial with respect to the chair conformation of the 1,3-dioxan ring. This conclusion is in agreement with previous conformational analysis of 5-heterosubstituted 1,3dioxanes, according to which the axial position of $\mathrm{H}-2$ and $\mathrm{H}-4$ is more shielded due to stronger folding of the O-C-O apex of the 1,3-dioxane ring. ${ }^{17}$ Consequently, the ensuing greater diaxial 1,3interaction is such that an aryl group attached at the carbon between the two oxygen of 1,3-dioxane ring prefers the equatorial position. ${ }^{17}$ Additional significant enhancements were observed by irradiation of the H-2 $(\delta 3.79 \mathrm{ppm}, 1 \mathrm{a})$. The observed n.O.e. enhancement of the H-4 $(\delta 3.66 \mathrm{ppm})$ and of $\mathrm{H}^{\text {acetal }}(\delta 5.63 \mathrm{ppm})$ confirmed the $2-\mathrm{H}$ and $4-\mathrm{H}$ axial position and the corresponding equatorial position of the $\mathrm{C}_{2}-\mathrm{C}_{1}$ and $\mathrm{C}_{4}-\mathrm{C}_{5}$ bonds. Relative configurations at $\mathrm{C}-4$ and $\mathrm{C}-5$ were confirmed by the small vicinal coupling constants shown by H-4 and H-5 (Table 1).

The chemical shifts and the coupling between H-3 and H-4 as well as H-4 and H-5, obtained by 1D HOHAHA spectra, could not be evinced from the COSY spectrum because the chemical shifts of H-4 and H-5 were almost identical, leading to non-first-order multiplets.

The assignment of the tetra-methyl ether $\mathbf{2}$ conformation was based on similar NMR features such as unique set and positions of signals for the protons, the value of coupling constants and n.O.e. enhancements (Table 4). Similar experiments in $\mathrm{D}_{2} \mathrm{O}$ led to the same considerations.

Furthermore, for samples $\mathbf{2 a}$ and $\mathbf{2 b}$ long-range correlations (resulting from carbons and protons linked via two to three intervening bonds) established by heteronuclear multiple-bond correlation (HMBC) spectra provided the resonances of the four methyl groups.

The observation in the HMBC spectrum of a two-bond correlation of methyl group at $\delta 3.40$ with C-3 $(\delta 72.2 \mathrm{ppm})$ allowed us to attribute this signal to $\mathrm{CH}_{3}$ bound to hydroxyl group in 3position. Similarly, the HMBC correlation from C-5 $(\delta 77.3 \mathrm{ppm})$ to methyl group at $\delta 3.37$, from $\mathrm{C}-1(\delta 71.3 \mathrm{ppm})$ to methyl group at $\delta 3.30$, and from C-6 $(\delta 70.4 \mathrm{ppm})$ to methyl group at $\delta 3.27$ revealed that these units are respectively $5-\mathrm{OCH}_{3}, 1-\mathrm{OCH}_{3}$, and $6-\mathrm{OCH}_{3}$.

In addition, these signals are confirmed by n.O.e. spectra, in particular the n.O.e. correlations of $3-\mathrm{OCH}_{3}(\delta 3.40)$ with $\mathrm{H}-1 \mathrm{a} ; 5-\mathrm{OCH}_{3}(\delta 3.37)$ with $\mathrm{H}-5, \mathrm{H}-6 \mathrm{a}$ and $6-\mathrm{OCH}_{3}(\delta 3.27) ; 1-\mathrm{OCH}_{3}(\delta$ 
3.30) with $\mathrm{H}-2$, H-5 and 5-OCH $3(\delta 3.37)$; 6- $\mathrm{OCH}_{3}(\delta 3.27)$ with $\mathrm{H}-4, \mathrm{H}-5, \mathrm{H}-6 \mathrm{a}$ and $\mathrm{H}^{\text {acetal }}$.

In conclusion, the unique set of signals for the protons of the 1,3-dioxane rings either in DMSO or $\mathrm{D}_{2} \mathrm{O}$ suggests a single conformation with the equatorial orientation of the furfurylidene group for compounds $\mathbf{1}$ and $\mathbf{2}$.

The axial position of the 3-hydroxy group and the equatorial position of the $\mathrm{C}_{4}-\mathrm{C}_{5}$ bond could generate intramolecular hydrogen bonding between the $6-\mathrm{OH}$ and $3-\mathrm{OH}$, the $3-\mathrm{OH}$ and $1-\mathrm{OH}$, the $5-\mathrm{OH}$ and the $3-\mathrm{OH}$, and consequently a set of stable pseudo-monocyclic and pseudo-bicyclic structures involving both 6 and/or 7 atoms should block the furan ring in an equatorial orientation. In a simulation computed by Low-Mode MD, these pseudo-cyclic conformations are 17 out of the 32 generated stable conformers, whereas 15 out of 32 correspond to a pseudo-monocyclic and 2 to a pseudo-bicyclic rings. Figure 4 reports the two pseudo-bicyclic conformations computed by Low-Mode MD simulation.
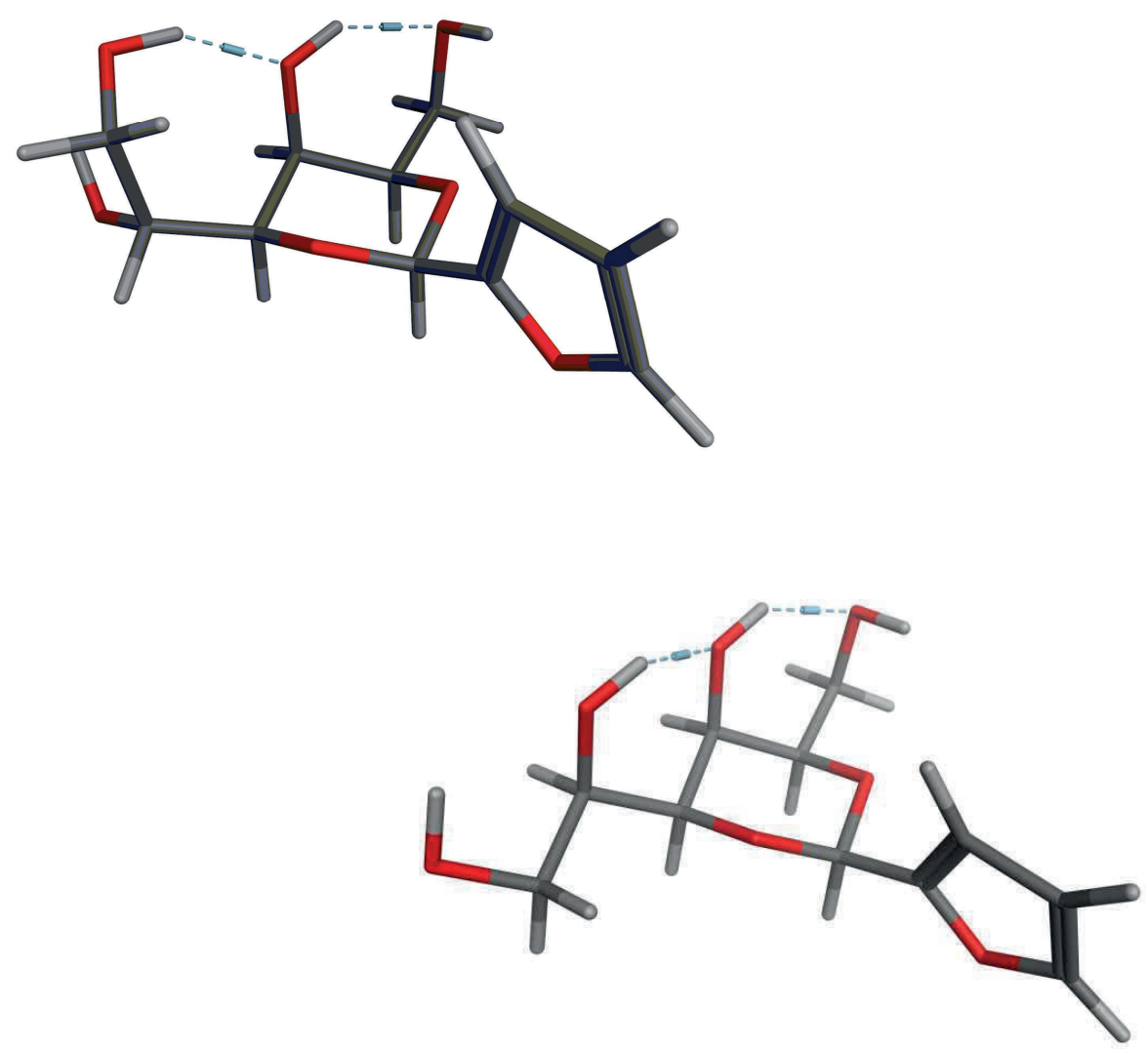

Figure 4. Stable pseudo-bicyclic conformations of compound 1, computed by Low-Mode MD simulation. On the top, a structure with 7- and 6-atom pseudo-rings (6-OH-3-OH and 3-OH-1-OH interactions); on the bottom, a structure with two 6-atom pseudo-rings (5-OH-3-OH and 3-OH-1$\mathrm{OH}$ interactions). 
In silico analysis of 2,4-furfurylidene-D-sorbitol (1) and its tetra-methyl ether 2

The lowest energy structures of compound $\mathbf{1}$ and 2, obtained by both on Density Functional Theory (DFT) based geometry optimization (A and D) and Low-Mode Molecular dynamics simulations (B and $\mathrm{E}$ ), are reported in Figure 5 and superimposed in $\mathrm{C}$ and $\mathrm{F}$.

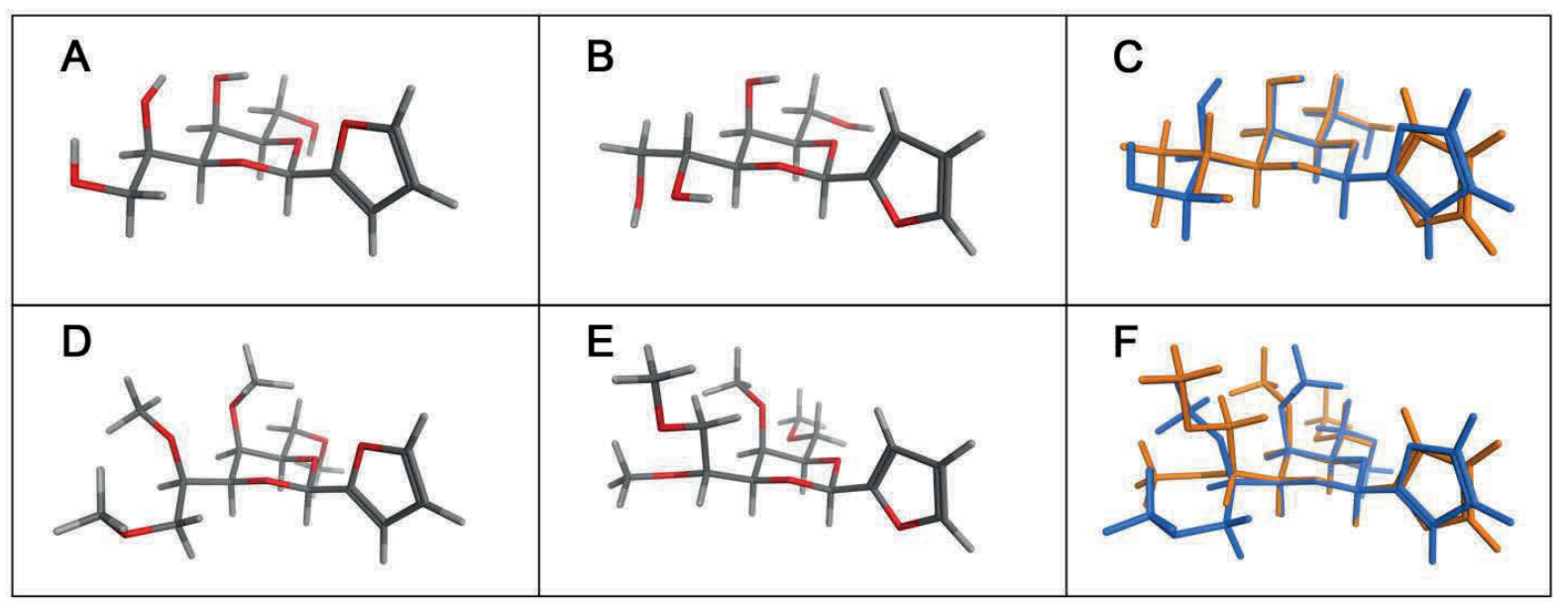

Figure 5. Minimum energy structures of compounds 1 (panels A and B) and 2 (panels D and E) obtained from DFT-based geometry optimization (panels A and D) and Low-Mode Molecular dynamics (panel B and E) and their superpositions (panles $\mathrm{C}$ and $\mathrm{F}$ ).

The structures of the two conformers obtained with different computational approaches retain the chair conformations of the 1,3-dioxane rings as well as the equatorial disposition of the furan ring. Molecular dynamics simulations evidence that, although the furan ring showed high rotational freedom along its equatorial axis, the same conformations are the most represented for both compounds $\mathbf{1}$ and $\mathbf{2}$. The rotational freedom associated to the furan ring has been analyzed by monitoring, during molecular dynamics, the $\mathrm{H}^{\text {acetal }}-\mathrm{H}^{3^{\prime}}$ distance for both compound $\mathbf{1}$ and $\mathbf{2}$, as reported in Figure 6. A careful analysis of the distance plots shows that the furan ring has two favoured orientations characterized by two discrete values in the $\mathrm{H}^{\text {acetal }}-\mathrm{H}^{3^{\prime}}$ distance. Compound 1 approximately equi-distributes its conformations between the two values (Figure 6, Panel A); differently, compound 2 prefers the conformation in which the $\mathrm{H}^{\text {acetal }}-\mathrm{H}^{3^{\prime}}$ distance is greater (Figure 6, Panel B). 

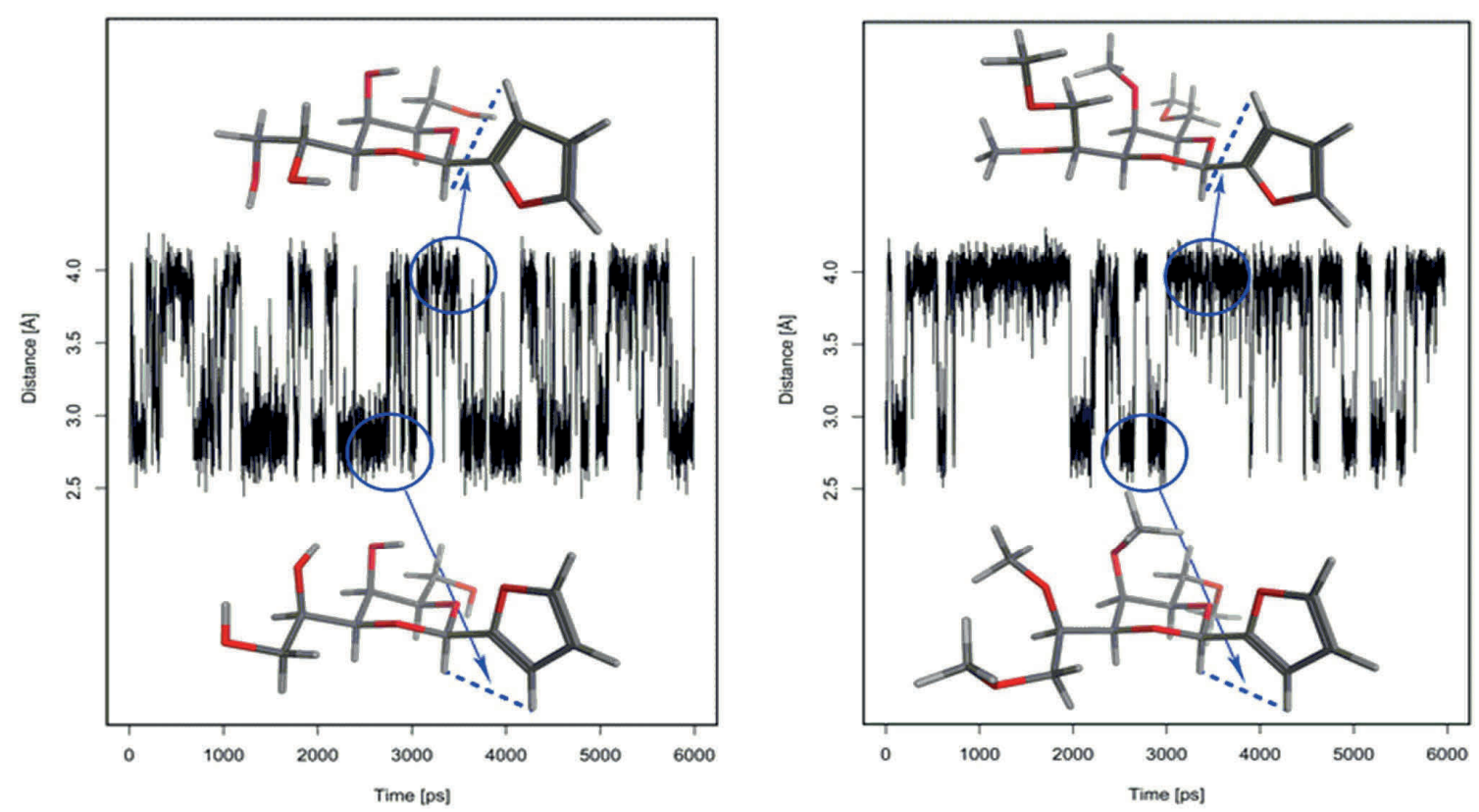

Figure 6. Panel A (left) reports the $\mathrm{H}^{\text {acetal }}-\mathrm{H}^{3^{\prime}}$ distance $v s$ simulated time plot for compound 1; panel B (right) reports the same measured distance for compound 2. Representative conformations for the max and min distance values are depicted at the top and the bottom of graphs.

The above differences observed for the furan ring orientation in compounds $\mathbf{1}$ and $\mathbf{2}$ can be proposed only by molecular dynamics simulations and suggest that the structure of the tetra-methyl ether 2 is more sampled in one conformationally stable structure, when compared to 2,4furfurylidene-D-sorbitol (1). Finally, a summary of the n.O.e. and H-H distances during MD simulation for compounds $\mathbf{1}$ and $\mathbf{2}$ is reported in Tables 3 and 4.

Table 3. Summary of the experimentally observed n.O.e. and of the $\mathrm{H}-\mathrm{H}$ distances at $310 \mathrm{~K}$, during MD simulation ${ }^{\text {a }}$ for compound $\mathbf{1}$

\begin{tabular}{lccc}
\hline Proton pair & n.O.e. & $\mathrm{MD}^{\mathrm{a}}$ & $\mathrm{H}-\mathrm{H}$ distance $(\AA)$ \\
\hline $\mathrm{H}^{\text {acetal }}-\mathrm{H}^{2}$ & + & + & 2.39 \\
$\mathrm{H}^{\text {acetal }}-\mathrm{H}^{3}$ & & + & 4.00 \\
$\mathrm{H}^{\text {acetal }}-\mathrm{H}^{4}$ & + & + & 2.38 \\
$\mathrm{H}^{\text {acetal }}-\mathrm{H}^{5}$ & & + & 4.72 \\
$\mathrm{H}^{\text {acetal }}-\mathrm{H}^{3}$ & + & + & 3.32 \\
$\mathrm{H}^{\text {acetal }}-\mathrm{H}^{4^{\prime}}$ & & - & 5.17 \\
$\mathrm{H}^{\text {acetal }}-\mathrm{H}^{5^{\prime}}$ & & - & 4.99 \\
$\mathrm{H}^{2}-\mathrm{H}^{4}$ & + & + & 2.56 \\
$\mathrm{H}^{2}-\mathrm{H}^{3}$ & & + & 2.51 \\
\hline
\end{tabular}


Table 3 (continued)

\begin{tabular}{lccc}
\hline Proton pair & n.O.e. & MD $^{\mathrm{a}}$ & $\mathrm{H}-\mathrm{H}$ distance $(\AA)$ \\
\hline $\mathrm{H}^{2}-\mathrm{H}^{5}$ & + & 4.45 \\
$\mathrm{H}^{2}-\mathrm{H}_{2}{ }^{6}$ & - & 5.44 \\
$\mathrm{H}^{3}-\mathrm{H}^{4}$ & + & 2.49 \\
$\mathrm{H}^{3}-\mathrm{H}^{5}$ & + & 2.63 \\
$\mathrm{H}^{3}-\mathrm{H}_{2}{ }^{4}$ & + & 4.82 \\
$\mathrm{H}^{4}-\mathrm{H}^{5}$ & + & 2.53 \\
$\mathrm{H}^{4}-\mathrm{H}^{6}$ & + & 3.13 \\
$\mathrm{H}^{5}-\mathrm{H}^{6}$ & + & 3.06 \\
$\mathrm{OH}^{3}-\mathrm{OH}^{5}$ & + & 2.53 \\
$\mathrm{OH}^{3}-\mathrm{OH}^{6}$ & - & 5.14 \\
$\mathrm{OH}^{5}-\mathrm{OH}^{6}$ & & + & 3.08 \\
\hline
\end{tabular}

${ }^{\mathrm{a}} \mathrm{H}-\mathrm{H}$ distance $<5 \AA$ for more than the $50 \%$ of the analyzed timeframes.

Table 4. Summary of the experimentally observed n.O.e. and of the H-H distances at $310 \mathrm{~K}$, during MD simulation ${ }^{\text {a }}$ for compound 2

\begin{tabular}{|c|c|c|c|}
\hline Proton pair & n.O.e. & $\mathrm{MD}$ & H-H distance $(\AA)$ \\
\hline $\mathrm{H}^{\text {acetal}}-\mathrm{H}^{2}$ & + & + & 2.37 \\
\hline $\mathrm{H}^{\text {acetal }}-\mathrm{H}^{3}$ & & + & 3.90 \\
\hline $\mathrm{H}^{\text {acetal }}-\mathrm{H}^{4}$ & + & + & 2.37 \\
\hline $\mathrm{H}^{\text {acetal }}-\mathrm{H}^{5}$ & & + & 4.65 \\
\hline $\mathrm{H}^{\text {acetal }}-\mathrm{H}^{3^{\prime}}$ & + & + & 3.68 \\
\hline $\mathrm{H}^{\text {acetal }}-\mathrm{H}^{4^{\prime}}$ & & - & 5.27 \\
\hline $\mathrm{H}^{\text {acetal }}-\mathrm{H}^{5^{\prime}}$ & & + & 4.76 \\
\hline $\mathrm{H}^{2}-\mathrm{H}^{4}$ & + & + & 2.54 \\
\hline $\mathrm{H}^{2}-\mathrm{H}^{3}$ & & + & 2.40 \\
\hline $\mathrm{H}^{2}-\mathrm{H}^{5}$ & + & + & 2.57 \\
\hline $\mathrm{H}^{2}-\mathrm{H}_{2}{ }^{6}$ & & + & 4.96 \\
\hline $\mathrm{H}^{3}-\mathrm{H}^{4}$ & & + & 2.39 \\
\hline $\mathrm{H}^{3}-\mathrm{H}^{5}$ & + & + & 2.93 \\
\hline $\mathrm{H}^{3}-\mathrm{H}_{2}{ }^{6}$ & & + & 3.63 \\
\hline $\mathrm{H}^{4}-\mathrm{H}^{5}$ & & + & 2.73 \\
\hline $\mathrm{H}^{4}-\mathrm{H}_{2}{ }^{6}$ & + & + & 2.74 \\
\hline $\mathrm{H}^{5}-\mathrm{H}_{2}{ }^{6}$ & & + & 2.17 \\
\hline $\mathrm{CH}_{3}{ }^{1}-\mathrm{H}^{2}$ & + & + & 3.86 \\
\hline $\mathrm{CH}_{3}{ }^{1}-\mathrm{H}^{5}$ & & - & 7.60 \\
\hline $\mathrm{CH}_{3}{ }^{3}-\mathrm{H}_{2}{ }^{1}$ & + & + & 3.46 \\
\hline
\end{tabular}


Table 4 (continued)

\begin{tabular}{lccc}
\hline Proton pair & n.O.e. & MD & H-H distance $(\AA)$ \\
\hline $\mathrm{CH}_{3}{ }^{3}-\mathrm{H}^{5}$ & + & + & 3.65 \\
$\mathrm{CH}_{3}{ }^{5}-\mathrm{H}^{5}$ & + & + & 2.48 \\
$\mathrm{CH}_{3}{ }^{5}-\mathrm{H}_{2}{ }^{6}$ & + & + & 4.58 \\
$\mathrm{CH}_{3}{ }^{5}-\mathrm{CH}_{3}{ }^{6}$ & + & + & 4.65 \\
$\mathrm{CH}_{3}{ }^{6}-\mathrm{H}^{4}$ & & - & 5.65 \\
$\mathrm{CH}_{3}{ }^{6}-\mathrm{H}^{5}$ & + & + & 3.86 \\
$\mathrm{CH}_{3}{ }^{6}-\mathrm{H}_{2}{ }^{6}$ & + & + & 2.37 \\
\hline
\end{tabular}

${ }^{\mathrm{a}} \mathrm{H}-\mathrm{H}$ distance $<5 \AA$ for more than the $50 \%$ of the analyzed timeframes.

Scavenging activity of 2,4-furfurylidene-D-sorbitol (1) and its tetramethyl ether 2 against hydroxyl radical by the 2-DR assay

Reactive oxygen species (ROS) are oxygen derived free radicals that are involved in a variety of oxidative damages from food deterioration to the pathogenesis of several human diseases. ${ }^{18,19}$

Several compounds that are able to contrast the damages of ROS action have shown beneficial effects in health and have been proposed also for the therapy of diseases related to the so called oxidative stress, defined as an unbalance between reactive species and physiological antioxidant defences. ${ }^{20,21}$ In this perspective, there is a special interest in research and development of antioxidant-based products suitable for dermatological application and skin care. ${ }^{22}$ Among ROS, hydroxyl radical $(\cdot \mathrm{OH})$ is the most instable and aggressive radical known in biology ${ }^{23}$ that reacts with virtually any organic compound with a reaction rate estimated in the $10^{7}-10^{10} \mathrm{M}^{-1} \mathrm{~s}^{-1}$ range, that nearly approach the diffusion controlled limit. ${ }^{24,25}$ The scavenging activity against this radical in vitro can be evaluated with several methods. ${ }^{26,27}$ Among them, the 2-deoxyribose (2-DR) degradation assay ${ }^{28,29}$ is still widely used due to its experimental simplicity. ${ }^{30}$

The details of the method are reported in supplementary material. However, the generation of the hydroxyl radical itself is not a simple process and many variables of the experimental protocol might influence the final outcome of the assay. ${ }^{30,31}$

For our evaluation of the scavenging activity of compounds $\mathbf{1}$ and $\mathbf{2}$ against hydroxyl radicals $(\cdot \mathrm{OH})$, we set up our experimental protocol of the 2-DR assay following the careful control of a few variables of the method discussed in a recent paper. ${ }^{30}$ Since the $\gamma$-pulsed radiolysis studies on the scavenging activity of compound $\mathbf{1}$ against the hydroxyl radical $(\cdot \mathrm{OH})^{11,12}$ had pointed out that addition of the radical to the $5^{\prime}$-position in the furan ring was the dominant reaction path, we selected 2-furaldehyde diethyl acetal 5 (Figure 7) as a simple example of non-cyclic furane acetal structurally similar to compound $\mathbf{1}$ and $\mathbf{2}$.<smiles>CCOC(OCC)c1ccco1</smiles>

5 
Figure 7. Structure of 2-furaldehyde diethyl acetal (5) tested by the 2-DR assay.

Results are presented in Figure 8 and show that the tetra-methyl ether 2 is more active than 2,4-furfurylidene-D-sorbitol (1). Both compounds are characterized by a cyclic structure and are more active scavengers than the non-cyclic acetal 5. Sorbitol (3) is less active than 2,4furfurylidene-D-sorbitol (1) and the other two tested compounds, the tetra-methyl ether 2 and 2furaldehyde diethyl acetal (5).

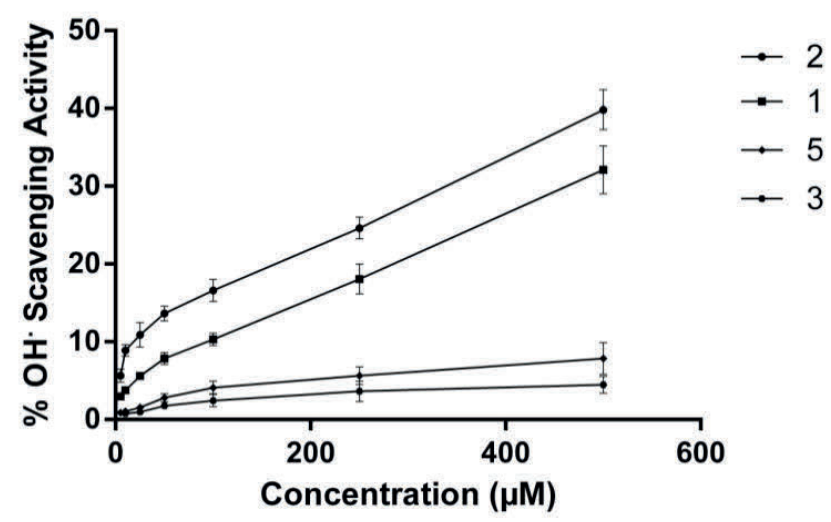

Figure 8. Hydroxyl radical scavenging activity of compounds $\mathbf{1}$ and 2, sorbitol (3), and 2furaldehyde diethyl acetal (5).

\section{Conclusions}

In this paper, we describe the synthesis of 2,4-furfurylidene-D-sorbitol (1) and its tetra-methyl ether 2 and show the results of a detailed NMR analysis that suggest that both compounds exist predominantly in one ring conformation. For both compounds, the preference for the equatorial disposition of the furan ring has been demonstrated. This was also confirmed by different in silico approaches, based both on Self Consistent Field (SCF) calculations (DFT based geometry optimization) and on classical molecular dynamics approaches.

Previous studies have proposed that the furan ring of compound $\mathbf{1}$ is responsible for its scavenging activity against hydroxyl radicals $(\cdot \mathrm{OH})$ and that the combination of the sorbitol backbone with the furan ring should be able to accelerate the re-organization of intermediate radicals and slow down the termination reactions. ${ }^{11}$ Our data confirm that compound $\mathbf{1}$ has a higher scavenging activity than D-sorbitol $\mathbf{3}$ alone and show that a cyclic furan acetal is more active than a non-cyclic furan acetal like 5. Therefore the scavenging activity of compounds $\mathbf{1}$ and $\mathbf{2}$ is apparently due to a synergic interaction of the D-sorbitol backbone with a conformationally locked acetal structure where the furan ring occupies a stable equatorial position. The interaction of the D-sorbitol backbone is independent by the presence $\mathrm{OH}$ group (compound 1) and is even 
reinforced by the presence of the $\mathrm{OCH}_{3}$ groups, as demonstrated by the highest scavenging activity of the tetra-methyl ether 2.

\section{Experimental Section}

General. All of the reagents and solvents, analytically pure, were obtained from Sigma-Aldrich and used as such without further purification. The progress of the reactions was monitored by analytical thin-layer chromatography (TLC) on pre-coated glass plates (silica gel 60 F254-plateMerck, Darmstadt, Germany) and the products were visualized by UV light. Elemental analyses were obtained for all intermediates and are within $\pm 0.4 \%$ of theoretical values. Melting points were determined with a Stuart Scientific SMP3 melting point apparatus. Infrared spectra were recorded using a Jasco FTIR 4100 spectrometer as a thin film on $\mathrm{NaCl}$ plates.

2,4-Furfurylidene-D-sorbitol (1). For the preparation of gram quantities, the experimental procedure described by Ruskin and Hockett ${ }^{9}$ was followed. Briefly, D-sorbitol (28 g, $0.1 \mathrm{~mol}$ ) was slowly added under vigorous stirring to $10 \mathrm{~mL}$ of $3 \mathrm{~N} \mathrm{H}_{2} \mathrm{SO}_{4}$ keeping the external temperature in the $25-30{ }^{\circ} \mathrm{C}$ range under nitrogen. Keeping the same temperature, $12.8 \mathrm{~g}$ of freshly distilled furfural $(0.13 \mathrm{~mol})$ were slowly added to the acidic solution of sorbitol. The formation of a solid material was controlled by continuous stirring for 4-6 hours. After one night, $30 \mathrm{~mL}$ of 2-propanol was added and the crude solid filtered off, twice washed with cold 2-propanol and finally washed with a cold solution of concentrated $\mathrm{NH}_{3}(1 \mathrm{~mL})$ in acetone $(20 \mathrm{~mL})$. Compound 1 was obtained as a white solid after crystallization from cold water in $70 \%$ yields $(27.3 \mathrm{~g}, 0.105 \mathrm{~mol})$; $\mathrm{mp} 190$ $192{ }^{\circ} \mathrm{C} ;[\alpha] \mathrm{D}^{25}+1.6\left(\mathrm{c} 2.0, \mathrm{H}_{2} \mathrm{O}\right)$ lit. ${ }^{6,9} \mathrm{mp} 190-191{ }^{\circ} \mathrm{C}\left(\right.$ from $\left.\mathrm{H}_{2} \mathrm{O}\right) ;[\alpha] \mathrm{D}^{25}+1.9$ (c 2.2, $\left.\mathrm{H}_{2} \mathrm{O}\right)$; IR (neat): $3276,1506,1304,1266,1110,936,814,798,741 \mathrm{~cm}^{-1}$.

2,4-Furfurylidene-D-sorbitol, tetra-methyl ether (2). Method 1: Reaction of 2,4furfurylidene-D-sorbitol (1) with $\left(\mathrm{CH}_{3} \mathrm{O}\right)_{2} \mathrm{SO}_{2}$. In a round-bottom flask, 2,4-furfurylidene-Dsorbitol $(1,2.6 \mathrm{~g}, 0.01 \mathrm{~mol})$ was added $50 \mathrm{~mL}$ of ethylene glycol dimethyl ether and to this mixture a solution of $\mathrm{NaOH}(50 \mathrm{~g}, 1.25 \mathrm{~mol})$ in water $(50 \mathrm{~mL})$ was added under mechanical stirring. Dimethylsulfate $\left(\left(\mathrm{CH}_{3} \mathrm{O}\right)_{2} \mathrm{SO}_{2}, 63 \mathrm{~g}, 0.5 \mathrm{~mol}\right)$ was added dropwise under control of the external temperature by an ice bath. After the addition of $\left(\mathrm{CH}_{3} \mathrm{O}\right)_{2} \mathrm{SO}_{2}$, the temperature was raised to $40{ }^{\circ} \mathrm{C}$ and the solution was kept under mechanical stirring for 2 hours. The reaction was checked by TLC (dichloromethane/methanol, 98:2) and for the work-up, the solution was concentrated by evaporation under vacuum and the crude reaction was poured in water $(200 \mathrm{~mL})$ containing sodium borohydride $\left(\mathrm{NaBH}_{4}, 200 \mathrm{mg}\right)$ as antioxidant. The temperature was brought to $0-4{ }^{\circ} \mathrm{C}$ and the crude product containing the compound $\mathbf{2}$ and inorganic salts was filtered and repeatedly washed with a cold water/methanol mixture (2:1 ratio). After several washing, the pure tetra-methyl ether $\mathbf{2}$ is obtained as a white solid in $38 \%$ yield $(1.2 \mathrm{~g}, 0.004 \mathrm{~mol})$; mp $63-64{ }^{\circ} \mathrm{C}$ (from $\left.\mathrm{H}_{2} \mathrm{O} / \mathrm{MeOH}\right)$; $[\alpha] \mathrm{D}^{25}$ +0.2 (c 2.0, $\mathrm{H}_{2} \mathrm{O}$ ); IR (neat): 2853, 2355, 1684, 1539, 1457, 1319, 1204, 1001, 803, $744 \mathrm{~cm}^{-1}$; Anal. Calcd for $\mathrm{C}_{15} \mathrm{H}_{24} \mathrm{O}_{7}$ : C, 56.95; H, 7.65. Found: C, 57.43; H, 7.78. 
Method 2. Reaction of 2,4-furfurylidene-D-sorbitol (1) with $\mathbf{C H}_{3} \mathbf{I}$. To a solution of 2,4furfurylidene-D-sorbitol $(1,2.6 \mathrm{~g}, 0.01 \mathrm{~mol})$ in $50 \mathrm{~mL}$ of anhydrous DMSO under nitrogen and mechanical stirring, powdered $\mathrm{NaOH}(10 \mathrm{~g}, 0.25 \mathrm{~mol})$ was added. Iodomethane $\left(\mathrm{CH}_{3} \mathrm{I}, 35.5 \mathrm{~g}\right.$, $0.25 \mathrm{~mol}$ ) was added dropwise under control of the external temperature by an ice bath. After the addition of $\mathrm{CH}_{3} \mathrm{I}$, the temperature was raised to $40{ }^{\circ} \mathrm{C}$, keeping the solution under mechanical stirring for 2 hours. The crude reaction was neutralized with $1.0 \mathrm{~N} \mathrm{HCl}$ and a saturated $\mathrm{NaCl}$ solution added to a final volume of $200 \mathrm{~mL}$. The solution was extracted with ethyl acetate $(5 \times 50$ $\mathrm{mL}$ ), the organic solution washed with chilled water and dried over sodium sulphate. Crystallization from cold water/methanol mixture (2:1 ratio) gave after several washing, the pure tetra-methyl ether 2 as a white solid in $34 \%$ yield $(1.07 \mathrm{~g}, 0.003 \mathrm{~mol})$.

NMR spectroscopy. NMR spectra were registered on a Bruker AVANCE 500 spectrometer equipped with a 5-mm broadband reverse probe and deuterium lock with field $z$-gradient operating at 500.13 and $125.76 \mathrm{MHz}$ for ${ }^{1} \mathrm{H}$ and ${ }^{13} \mathrm{C}$, respectively from $40 \mathrm{mM}$ solutions $(20 \mu \mathrm{mol}$ of product dissolved in $0.5 \mathrm{ml}$ of solvent). All NMR spectra were recorded at $298 \mathrm{~K}$ in DMSO- $d_{6}$ (isotopic enrichment 99.95\%) or $\mathrm{D}_{2} \mathrm{O}$ (isotopic enrichment 99.98\%) solution and the chemical shifts were reported on a $\delta(\mathrm{ppm})$ scale. The proton spectra calibration of the chemical shift scale was performed by adjusting the residual DMSO to $2.49 \mathrm{ppm}$ and $\mathrm{H}_{2} \mathrm{O}$ signals to $4.70 \mathrm{ppm}(298 \mathrm{~K}, 40$ $\mathrm{mM}, \mathrm{pH}=7.0$ ). The chemical shifts of the carbon spectra in $\mathrm{D}_{2} \mathrm{O}$ were referenced to external TSP$d_{4}$ (3-(trimethylsilyl)propionic-2,2,3,3- $d_{4}$ acid sodium salt) at $0.00 \mathrm{ppm}$ and in DMSO at 39.50 (central line). Acquisition parameters for 1D were as follows: ${ }^{1} \mathrm{H}$ spectral width of $5000 \mathrm{~Hz}$ and $32 \mathrm{~K}$ data points providing a digital resolution of ca. $0.305 \mathrm{~Hz}$ per point, relaxation delay $2 \mathrm{~s} ;{ }^{13} \mathrm{C}$ spectral width of $29412 \mathrm{~Hz}$ and $64 \mathrm{~K}$ data points providing a digital resolution of ca. $0.898 \mathrm{~Hz}$ per point, relaxation delay $2.5 \mathrm{~s}$. The experimental error in the measured ${ }^{1} \mathrm{H}-{ }^{1} \mathrm{H}$ coupling constants was $\pm 0.5 \mathrm{~Hz}$. For two-dimensional experiments, standard Bruker microprograms using gradient selection (gs) were applied. Gs-COSY-45 and phase sensitive gs-NOESY experiments were acquired with $512 t_{1}$ increments; $2048 t_{2}$ points; spectral/spectrum width $10.0 \mathrm{ppm}$. The gs-NOESY experiments were performed with a mixing time of $0.800 \mathrm{~s}$ on samples degassed under a flush of argon in a screw-cap sample tube. There were not significant differences in the results obtained at different mixing times $(0.5-2.0 \mathrm{~s})$. The acquisition data for gHSQC and gHMBC experiments were obtained with $512 t_{1}$ increments; $2048 t_{2}$ points; spectral/spectrum width $10.0 \mathrm{ppm}$ for ${ }^{1} \mathrm{H}$ and $220 \mathrm{ppm}$ for ${ }^{13} \mathrm{C}$. Delay values were optimized for ${ }^{1} J_{\mathrm{C}, \mathrm{H}} 140.0 \mathrm{~Hz}$ and ${ }^{n} J_{\mathrm{C}, \mathrm{H}} 3.0 \mathrm{~Hz}$. Zero filling in $\mathrm{F}_{1}$ to $1 \mathrm{~K}, \pi / 2$ shifted sine-bell squared (for gHSQC) or sinebell (for gHMBC) apodization functions were used for processing. For overlapped signals of hydrogen atoms the 1D homonuclear Hartmann-Hahn coherence transfer technique (HOHAHA) ${ }^{16}$ was used to obtain the chemical shifts and coupling constants.

\section{Molecular Modelling}

Molecular dynamics simulations. Both compounds were built by the MOE Builder Module and minimized using MMFF94x force field, down to a RMS value of $0.1 \mathrm{kcal} / \mathrm{mol} \AA^{2}$. 
Molecular dynamics simulations were carried out in a water droplet, containing 540 molecules of water, using a wall restraint to enclose all the water solvent molecules inside a spheric space during simulations. ${ }^{32}$ Production stage for both molecular dynamics simulations was performed with a timestep of $0.5 \mathrm{ps}$, for a total simulated time of $3 \mathrm{~ns}$.

The trajectories produced were subsequently analyzed with an R-script, measuring the $\mathrm{H}-\mathrm{H}$ distances with an interactive tool. A limit value of $5 \AA$ for more than the $50 \%$ of the analyzed timeframes was considered as a positive n.O.e.

Low-Mode Molecular dynamics simulations. In order to compute a minimized, stable structure for both the investigated molecules, we carried out two Low-Mode Molecular dynamics simulations, MOE Conformational Search program of the Conformations module, which uses an efficient implicit method for estimating the low-frequency modes and is based on the attenuation of high-range velocities as described in detail. ${ }^{33}$

DFT-based optimization geometry. In order to evaluate the electronic features of the investigated molecules, a geometry optimization in the gas phase with an approach based on density functional theory (DFT/B3LYP/6-31G*) was performed with GAMESS. ${ }^{34,35}$

\section{2-DR assay}

Preparation of stock solutions of the reagents. Stock solutions of 2-deoxyribose $(25 \mathrm{mM})$ and phosphate buffer $10 \mathrm{mM}$ (pH 7.4) were prepared and kept in a cold room at 4- $6{ }^{\circ} \mathrm{C}$. Stock solution of EDTA $(10 \mathrm{mM})$ was prepared at $\mathrm{pH} 7.0$ according to the methods of Lopes et al. ${ }^{36}$ and kept at room temperature.

Fresh aqueous stock solution of $10 \mathrm{mM} \mathrm{FeCl}_{3}, 2 \mathrm{mM} \mathrm{H}_{2} \mathrm{O}_{2}$ and $0.5 \mathrm{mM}$ ascorbic acid was prepared daily. $\mathrm{FeCl}_{3}$ was dissolved in $0.1 \mathrm{M} \mathrm{HCl}$ and $0.5 \mathrm{~mL}$ of $10 \mathrm{mM} \mathrm{FeCl}_{3}$ was mixed with $9.5 \mathrm{~mL}$ of $10 \mathrm{mM}$ EDTA to obtain $\mathrm{Fe}^{3+}$-EDTA complex $\left(500 \mu \mathrm{M} \mathrm{Fe}^{3+}\right)$. Fresh solutions of compounds to be tested were prepared daily. Compounds $\mathbf{1}$ and $\mathbf{2}$, sorbitol (3) were dissolved in distilled water. A solution of 2-furaldehyde diethyl acetal (5) was obtained after treatment with ultrasounds (15 min, $\left.40{ }^{\circ} \mathrm{C}\right)$. A stock solution of $1 \% \mathrm{TBA}(\mathrm{w} / \mathrm{v})$ was prepared in $50 \mathrm{mM} \mathrm{NaOH}$ and used within 1 week.

Experimental protocol. The hydroxyl radical scavenging activity of compounds 1, 2, 3, and 5 was evaluated as described by Aruoma ${ }^{37}$ and modified as reported in ref. 28. In a screw capped glass tube, $100 \mu \mathrm{l}$ of $\mathrm{Fe}^{3+}$-EDTA, $100 \mu \mathrm{l}$ of $\mathrm{H}_{2} \mathrm{O}_{2}, 200 \mu \mathrm{l}$ of 2-deoxyribose and $200 \mu \mathrm{l}$ of $10 \mathrm{mM}$ phosphate buffer ( $\mathrm{pH}$ 7.4) were sequentially added. To the reaction mixture, $200 \mu \mathrm{l}$ of a solution of the tested compounds was added in order to reach final concentrations of $5,10,25,50,100,250$ and $500 \mu \mathrm{M}$. At the end, $200 \mu \mathrm{l}$ of ascorbic acid were added to a final volume of $1 \mathrm{~mL}$ to start the reaction at $25{ }^{\circ} \mathrm{C}$. After $40 \mathrm{~min}$ the reaction was stopped by addition of $1 \mathrm{~mL}$ of $4 \%(\mathrm{v} / \mathrm{v})$ phosphoric acid, and then $1 \mathrm{~mL}$ of $1 \%(\mathrm{w} / \mathrm{v})$ TBA was added. The tubes were placed in hot water $\left(90-95{ }^{\circ} \mathrm{C}\right.$ ) to develop a pink color. After $15 \mathrm{~min}$, the tubes were removed from the hot water, cooled at room temperature and the absorbance was recorded at $532 \mathrm{~nm}$. The used apparatus was a spectrophotometer UV/VIS DU 640 (Beckman, Pasadena, USA). Each assay was performed in triplicate and the percentage of hydroxyl radical scavenging activity was calculated from the 
relationship:

$$
\text { Scavenging activity }(\%)=\left[\left(\mathrm{A}_{0}-\mathrm{A}_{\mathrm{s}}\right) / \mathrm{A}_{0}\right] \times 100
$$

where $A_{s}$ is the absorbance value of the sample and $A_{0}$ is the absorbance value of a blank sample, prepared with the same protocol used for the samples to be evaluated, with distilled water instead of the compound to be tested. The absorbance of the blank, recorded at $532 \mathrm{~nm}$, ranged between 0.8 and 1 . Results are reported as the percentage scavenging activities versus tested compound concentrations.

\section{Supplementary Information Available}

${ }^{1} \mathrm{H}$ and ${ }^{13} \mathrm{C}$-NMR spectra of 2,4-furfurylidene-D-sorbitol (1) and its tetra-methyl ether 2 in $\mathrm{D}_{2} \mathrm{O}$ and $\mathrm{DMSO}-d_{6}$ and a description of the 2-deoxyribose degradation assay are available.

\section{Acknowledgements}

We thank Dr. Alberto Milanese (Insubria Biopark, Gerenzano, Italy) for the preparation of analytically pure samples of compounds $\mathbf{1}$ and $\mathbf{2}$.

\section{References}

1. Bertelli, V. European Patent 345362 A1, 1989; Chem. Abstr. 1990, 113, 197668.

2. Silverberg, J.I. Am. J. Clin. Dermatol., 2014, 15, 149-164.

http://dx.doi.org/10.1007/s40257-014-0062-z

3. Pellanda, C.; Weber, M.; Bircher, A.; Surber, C. Dermatology, 2005, 211, 338-340. http://dx.doi.org/10.1159/000088504

4. Vena, G.A.; Cassano, N.; Mastrolonardo, M.; Loconsole, F.; Coviello, C.; Arpaia, N. G. Ital. Dermatol. Venereol., 1998, 133, 373-380.

5. Gers-Ballach, H.; Müller, A.; Stäb, F.; Sauermann, G.; Untiedt, S. Parfum. Und Kosmet., 1996, 77, 460-463.

6. Bonner, T.G.; Bourne, E.J.; Harwood, S.E.; Lewis, D. J. Chem. Soc. C Org., 1966, 22292233.

7. Bredereck, H.; Papademetriu, T. Berichte Der Dtsch. Chem. Gesellschaft (A B Ser.), 1937, 70, 797-802.

8. García, P.A.; Velasco, R.; Barba, F. Synth. Commun., 1991, 21, 1153-1161. http://dx.doi.org/10.1080/00397919108021034

9. Ruskin, S.L.; Hockett, R.C. U.S. Patent 2853 495, 1958; Chem. Abstr. 1959, 53, 5150.

10. Bader, S.; Carinelli, L.; Cavalletti, T.; Giuliani, A.L.; Traniello, S. Int. J. Cosmet. Sci., 1990, 
$12,1-4$.

11. Emmi, S.S.; D’Angelantonio, M.; Poggi, G.; Russo, M.; Beggiato, G.; Larsen, B. J. Phys. Chem. A, 2002, 106, 4598-4607. http://dx.doi.org/10.1021/jp014304z

12. Russo, M.; Sgariglia, L.; D’Angelantonio, M.; Emmi, S.S. Res. Chem. Intermed., 2004, 30, $253-267$. http://dx.doi.org/10.1163/156856704323033996

13. Russo, M.; Poggi, G.; Navacchia, M.L.; D’Angelantonio, M.; Emmi, S.S. Res. Chem. Intermed., 2006, 32, 153-170. http://dx.doi.org/10.1163/156856706775372816

14. Zanoli, P.; Baggio, G.; Poggioli, R. Agents Actions, 1982, 12, 521-526. http://dx.doi.org/10.1007/BF01965937

15. Zanoli, P.; Poggioli, R.; Sannicola, B.C. Arzneimittelforschung., 1979, 29, 527-532.

16. Davis, D.G.; Bax, A. J. Am. Chem. Soc., 1985, 107, 7197-7198. http://dx.doi.org/10.1021/ja00310a085

17. Abraham, R.J.; Banks, H.D.; Eliel, E.L.; Hofer, O.; Kaloustian, M.K. J. Am. Chem. Soc., 1972, 94, 1913-1918. http://dx.doi.org/10.1021/ja00761a021

18. Frankel, E.N.; German, J.B. J. Sci. Food Agric., 2006, 86, 1999-2001. http://dx.doi.org/10.1002/jsfa.2616

19. Valko, M.; Leibfritz, D.; Moncol, J.; Cronin, M.T.D.; Mazur, M.; Telser, J. Int. J. Biochem. Cell Biol., 2007, 39, 44-84. http://dx.doi.org/10.1016/j.biocel.2006.07.001

20. Aruoma, O.I. J. Am. Oil Chem. Soc., 1998, 75, 199-212. http://dx.doi.org/10.1007/s11746-998-0032-9

21. Firuzi, O.; Miri, R.; Tavakkoli, M.; Saso, L. Curr. Med. Chem., 2011, 18, 3871-3888. http://dx.doi.org/10.2174/092986711803414368

22. Andreassi, M.; Andreassi, L. J. Cosmet. Dermatol., 2004, 2, 153-160. http://dx.doi.org/10.1111/j.1473-2130.2004.00075.x

23. Slater, T.F. Biochem. J., 1984, 222, 1-15. http://dx.doi.org/10.1042/bj2220001

24. Walling, C. Acc. Chem. Res., 1975, 8, 125-131. http://dx.doi.org/10.1021/ar50088a003

25. Buxton, G. V.; Greenstock, C.L.; Helman, W.P.; Ross, A.B. J. Phys. Chem. Ref. DATA, 1988, $17,513-886$. http://dx.doi.org/10.1063/1.555805

26. Singh, S.; Singh, R.P. Food Rev. Int., 2008, 24, 392-415. http://dx.doi.org/10.1080/87559120802304269

27. Burns, J.M.; Cooper, W.J.; Ferry, J.L.; King, D.W.; DiMento, B.P.; McNeill, K.; Miller, C.J.; Miller, W.L.; Peake, B.M.; Rusak, S.A.; Rose, A.L.; Waite, T.D. Aquat. Sci., 2012, 74, 683- 
734.

http://dx.doi.org/10.1007/s00027-012-0251-x

28. Gutteridge, J.M.C. FEBS Lett., 1981, 128, 343-346.

http://dx.doi.org/10.1016/0014-5793(81)80113-5

29. Halliwell, B.; Gutteridge, J.M.C. FEBS Lett., 1981, 128, 347-52.

http://dx.doi.org/10.1016/0014-5793(81)80114-7

30. Genaro-Mattos, T.C.; Dalvi, L.T.; Oliveira, R.G.; Ginani, J.S.; Hermes-Lima, M. Biochim. Biophys. Acta, Gen. Subj., 2009, 1790, 1636-1642.

http://dx.doi.org/10.1016/j.bbagen.2009.09.003

31. Gutteridge, J.M.C.; Halliwell, B. Trends Biochem. Sci., 1990, 15, 129-135. http://dx.doi.org/10.1016/0968-0004(90)90206-Q

32. Rocco, A.G.; Sensi, C.; Gianazza, E.; Calabresi, L.; Franceschini, G.; Sirtori, C.R.; Eberini, I. J. Mol. Graph. Model., 2010, 29, 406-414.

http://dx.doi.org/10.1016/j.jmgm.2010.08.002

33. Labute, P. J. Chem. Inf. Model., 2010, 50, 792-800.

http://dx.doi.org/10.1021/ci900508k

34. Schmidt, M.W.; Baldridge, K.K.; Boatz, J.A.; Elbert, S.T.; Gordon, M.S.; Jensen, J.H.; Koseki, S.; Matsunaga, N.; Nguyen, K.A.; Su, S.; Windus, T.L.; Dupuis, M.; Montgomery, J.A. J. Comput. Chem., 1993, 14, 1347-1363.

http://dx.doi.org/10.1002/jcc.540141112

35. Gordon, M.S.; Schmidt, M.W. In Theory and Applications of Computational Chemistry, Dykstra, C. E., Frenking, G., Kim, K. S., Scuseria, G. E., Eds; Elsevier: Amsterdam, 2005; pp 1167-1189.

http://dx.doi.org/10.1016/B978-044451719-7/50084-6

36. Lopes, G.K.B.; Schulman, H.M.; Hermes-Lima, M. Biochim. Biophys. Acta - Gen. Subj., 1999, 1472, 142-152.

http://dx.doi.org/10.1016/S0304-4165(99)00117-8

37. Aruoma, O.I. In Oxygen Radicals in Biological Systems Part C Academic Press, 1994; Vol.233, pp 57-66. 